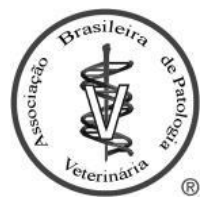

\title{
Editorial
}

\section{Special Editorial - 10 years of the BJVP}

\author{
Antonio C. Alessi ${ }^{1}$, Dominguita L. Graça ${ }^{2}$ \\ ${ }^{1}$ BJVP Editor 2007 - 2011 (antonio.alessi@gmail.com). \\ ${ }^{2}$ BJVP Editor 2011 - 2014 (dlgraca@gmail.com).
}

The union of Brazilian Veterinary Pathologists had great impulse by the time of the First National Meeting of Veterinary Pathology in 1983 in Campo Grande, State of Mato Grosso do Sul. Due to the success of the first meeting, since then there have been regularly biannual meetings. Because of the increasing importance of these meetings they have been renamed as Brazilian Congress of Veterinary Pathology since 2011.

The continued union of pathologists stimulated the establishment of the Brazilian Association of Veterinary Pathology (ABPV) in July 2006. The ABPV took on various relevant activities, among them pursuing the statutory goal of publicizing scientific investigation concerning veterinary pathology. Therefore, in 2007 the electronic journal Brazilian Journal of Veterinary Pathology (BJVP) was created; the first volume with two issues was published in 2008.

The electronic-only format of the BJVP was adopted following the tendency of the time and it is a current practice today. The determining factor for this format was the preclusion of paper and mail costs. The universal divulgation of papers through an open access policy, made the electronic format very convenient. Additionally, the journal was published all and only in an English version, again, to permit a large universal divulgation.

The English electronic format made the BJVP an important Brazilian scientific vehicle of international characteristics. In 2011, the electronic access had the identified origin of 32 countries (Index Copernicus). Thus, submissions came not only from Brazilian studies, but also from other countries in Latin America, Europe, and Asia. The BJVP success was also due to the dedicated work of researchers of many Brazilian institutions as well as from abroad who compose the Editorial Board and the Scientific Committee.

After the ISSN obtainment it was required intense work to extend the journal indexation including
Qualis/Capes, with the current B3 classification. The number of submissions is increasing. All manuscripts are subjected to review by peers and approval by the Editor since the presentation follows the rules of the journal, the results are original and relevant and discussion and conclusions are solidly supported. Along the last two years, $47 \%$ of all submitted manuscripts have been rejected.

Case Report publications represent a large proportion of papers since they reflect the day by day pathological diagnoses made up by hundreds of researchers who perform diagnostic veterinary pathology. Their work embraces the diversity of production animals, pets and wild species. The journal publishes full articles on natural and experimental diseases, reviews, brief communications, and letters to the Editor. Currently the BJVP publishes three issues per year.

The impact factor, reflection of citation index, is increasing and comparable to the presented by traditional publications of many decades of existence. Always updated, the journal will continue to line up with all most prestigious online publications. In summary, in the first decade of existence the BJVP has fulfilled the statutory ABPV publishing mission and goes on being an important Brazilian journal of international scope. 